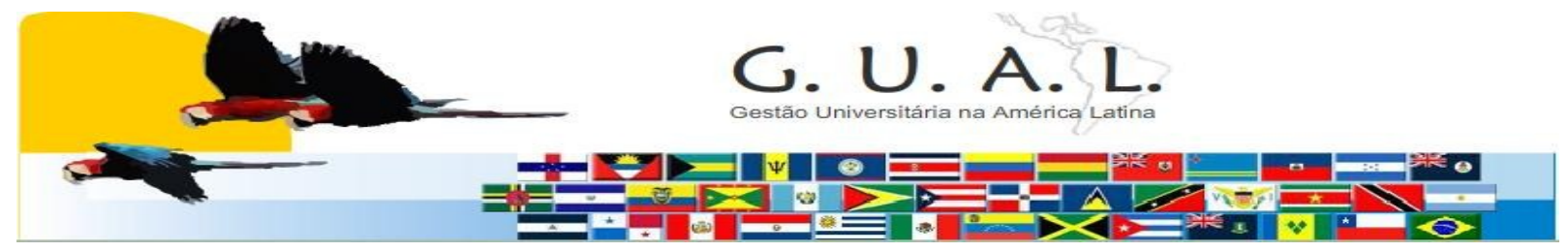

ISSN 1983-4535

\title{
ESTRATÉGIAS DE MARKETING APLICADAS A INSTITUIÇÕES DE EDUCAÇÃO SUPERIOR PRIVADAS
}

\author{
Vera Lucia Telles Scaglione, Bacharel \\ Faculdade Paulista de Artes - FPA \\ vera.fpa@terra.com.br \\ Vera Toledo Piza, Doutora \\ Faculdade Paulista de Artes - FPA \\ vtpiza@uol.com.br
}

\section{RESUMO}

A partir do início do século XXI, muitas mudanças vêm ocorrendo no cenário cultural brasileiro, em especial no que se refere à busca pelo ensino superior. Isso se deve à ampliação do poder aquisitivo das classes sociais, que buscam, na educação superior, tanto o crescimento profissional quanto a realização pessoal. Tal fenômeno gerou o crescimento do número de instituições de educação superior no país e, consequentemente, maior oferta de vagas em todas as áreas, tanto nas universidades públicas quanto nas particulares. Este texto faz uma análise dessa realidade, com base em pesquisa bibliográfica desenvolvida por autores da área de marketing, concluindo que resta às instituições de ensino particulares procurar o apoio do marketing educacional. Este vai sugerir estratégias adequadas para facilitar a captação e manutenção dos alunos em seus quadros. Esses alunos, uma vez satisfeitos com a qualidade de ensino que lhes é oferecida, passam a atuar como agentes de marketing na captação de novos alunos, levando à sociedade as qualidades dos serviços que the foram prestados pela Instituição.

Palavras-chave: Competitividade. Desempenho. Ensino superior. Estratégias de marketing. 


\section{INTRODUÇÃO}

A partir do início do século XXI, muitas mudanças culturais vêm ocorrendo no cenário brasileiro, as quais abrangem os campos da ciência, da tecnologia, da vida social, econômica e educacional do nosso povo, o que tem proporcionado às pessoas das diversas classes socioeconômicas o acesso aos mais variados bens de consumo. Essas mudanças, respaldadas pelo crescimento econômico do país, atingiram em cheio o campo da educação, levando grande parcela da população a procurar os níveis mais elevados de escolaridade, da educação básica ao ensino superior.

Essa busca pela educação superior em nosso país tem elevado a um patamar recorde o número de instituições privadas criadas a partir do final da década de 90. Atualmente, as instituições de ensino superiores (IES) privadas representam 90\% do total de IES brasileiras e absorvem aproximadamente 1,2 milhões de novos alunos todos os anos.

Entretanto, a expectativa pela demanda de vagas nos cursos superiores não foi diretamente proporcional ao aumento do número daquelas oferecidas, o que acabou gerando o aumento das vagas ociosas na maioria das IES, em especial nas particulares. Ou seja, segundo dados do INEP (2008), o excesso de oferta de vagas é bastante superior à demanda atual.

Se formos procurar as causas dessa questão, vamos esbarrar na facilidade com que a Lei n n $^{9.394}$ de 1996, de Diretrizes e Bases da Educação (LDB), permitiu a abertura de IES por todo o país, o que provocou verdadeira disputa pelos estudantes por parte das Instituições e tornou o ambiente educacional brasileiro bastante competitivo.

Uma vez em busca da competitividade própria dos mercados capitalistas, e levando-se em conta a regulamentação governamental, as instituições educacionais, destacando-se as particulares, reforçam a idéia de um mercado educacional brasileiro que busca aproximar-se “cada vez mais de um mercado onde a qualidade dos serviços e a satisfação dos clientes são fundamentais para a sobrevivência das IES" (TONTINI \& DOMINGUES, 2005). Em outras palavras, a educação, de modo geral, passa a ser encarada como um produto a ser ofertado, e as Instituições de Ensino devem se empenhar para desenvolver as mais diversas estratégiascaptação de clientes.

Com relação à educação superior, observa-se o fato de que no Brasil, entre 2005 e 2010, o crescimento populacional, na faixa etária de 18 a 24 anos, encolheu $24 \%$, reduzindo a população com algum potencial de investir em formação superior (LIMA, 2006). Logo, a 
quantidade de candidatos potenciais para custear a educação superior privada mostra-se menor do que o número de vagas disponíveis, ou seja, bem diferente de outras épocas, pois agora a oferta de vagas supera a demanda.

Uma vez abrindo seu capital para investidores, muitas IES acabam por transformar a educação e o ensino em mercadorias, e passam a competir no mercado de ações com seus produtos, nos mesmos moldes que as demais empresas privadas de capital aberto (MUND et al, 2001). Essa atitude, por si, minimiza o papel do educador, que passa a ser um mero divulgador de conhecimentos, menos preocupado com a educação em si e mais um instrumento sujeito aos bons ou maus ventos das tendências do mercado consumidor.

Ainda, neste cenário já bem difícil, ao lado das universidades "empresariais", surgem também as universidades virtuais, que invadem o nicho de mercado ocupado pelas IES tradicionais. Normalmente, essas novas instituições possuem grande capacidade de investimento e focam-se nos segmentos tradicionais, concorrendo com as IES privadas na captação dos mesmos estudantes que nestas costumam matricular-se (KALZBECK, 2003 apud MEYER Jr., 2003). Diante de tal cenário, as IES privadas terão de rever suas estruturas organizacionais, tendo em vista o aumento de competitividade, perante o qual se deparam.

Este texto procura fazer uma análise dessa situação e propor alternativas para encontrar as devidas soluções. Como fundamento desse estudo e das propostas apresentadas, foi feita uma pesquisa bibliográfica baseada em obras de autores destacados na área de marketing, em especial ligados ao marketing educacional. Da análise dos resultados, concluímos que há necessidade de as IES privadas reverem com urgência os seus modelos de gestão e estratégias de marketing, conforme demonstramos a seguir.

\section{ESTRATÉGIAS DE MARKETING}

Marketing pode ser definido como o processo de planejamento, execução e controle de produtos como meio para alcançar os objetivos organizacionais.

As primeiras definições para marketing tinham como foco produtos tangíveis. Apenas mais tarde, em 1969, os autores KOTLER e LEVY (1969) ampliaram essa definição, expandindo o conceito de marketing, o qual passou a incluir as organizações sem fins lucrativos. No entanto, no campo da Educação, há uma grande resistência dos gestores educacionais, em geral, na aceitação do marketing nessa área. 
Para Kotler (1992), Marketing é uma atividade humana orientada a satisfazer necessidades e desejos através do processo de trocas. De acordo com a American Marketing Association (AMA): "Marketing é o conjunto de atividades, processos e instituições que têm por objetivo criar, comunicar, entregar e promover trocas que tenham valor para os consumidores, clientes, parceiros de negócio e a sociedade como um todo".

A definição de marketing aplicada a serviços é bem mais complexa do que aquela aplicada a produtos tangíveis. Dentre as suas a características básicas podem-se destacar: intangibilidade, variabilidade, inseparabilidade e perecibilidade.

No que se refere à sua intangibilidade, a dificuldade está em que os serviços não podem ser vistos, sentidos ou testados antes da compra. Logicamente, estes possuem algumas variáveis tangíveis, concretas, as quais muitas vezes servem como suporte ou apoio auxiliar do Marketing na venda de um serviço ou produto.

Essas características aplicam-se aos serviços prestados pelas IES, com a dificuldade de que o futuro aluno somente poderá experimentá-los e deles formular um conceito bem depois do momento em que fez a sua escolha. E, em se tratando de instituição de ensino, cujos resultados finais aparecem depois de vários anos, a avaliação final somente poderá ser definida após a conclusão do curso escolhido.

Quanto aos aspectos tangíveis dessa prestação de serviços, pode-se destacar a infraestrutura da IES, isto é, suas instalações, tais como suas salas de aulas, seus laboratórios e sua biblioteca. Esses fatores podem conferir certo grau de confiabilidade à IES, o que é útil no momento de conquista de um novo aluno. Mas a boa infraestrutura também não garantirá ao candidato uma escolha segura, pois a prestação de serviços que será oferecida vai bem além dos seus primeiros contatos ou da sua primeira impressão.

Quanto à variabilidade dos serviços, entra-se na questão da qualidade do serviço prestado, ou seja, a prestação deste vai variar em função de quem o presta, assim como de quem o recebe, o cliente. Vale ressaltar que além da questão dos atores envolvidos, outros fatores também concorrem para determinação da qualidade de um serviço, tais como: quando, onde e como o serviço é executado. Até certo ponto, essa variabilidade pode ser considerada positiva, pois permite a customização e a adaptação aos desejos dos clientes. O lado negativo dessa característica é a dificuldade existente na padronização dos serviços executados.

Rev. GUAL., Florianópolis, v.4, n. 2, p.167-181, mai/ago. 2011 
Para as IES que precisam contar com uma quantidade muito grande de funcionários para cumprir sua complexa missão, torna-se uma tarefa bastante árdua garantir que todo esse contingente envolvido prime sempre pela boa qualidade dos serviços. Outro ponto é que a prestação de serviços nas IES ocorre durante um longo período de tempo, o que eleva sobremaneira a dificuldade de se manter a prestação de serviços dentro do mesmo padrão, evitando-se deslizes.

No que diz respeito à inseparabilidade dos serviços, pode-se considerar a estreita ligação destes com o fator humano, isto é, os serviços não podem ser separados dos seus fornecedores e sua qualidade está estreitamente ligada aos mesmos. Pensando-se no contexto educacional, uma aula dada por um professor jamais será idêntica a outra, ainda que ambas abordem o mesmo conteúdo.

A quarta característica dos serviços é a sua perecibilidade, isto é, o fato de que os serviços acontecem num determinado momento e, independentemente de serem ou não utilizados, não poderão ser estocados. Se um aluno perder uma aula, não há como repô-la de maneira idêntica àquela dada anteriormente, se pensarmos na aula como um evento único no sentido de interação, que ocorre a partir da relação de um docente com um grupo de alunos.

Mais difícil que definir os conceitos de marketing é colocá-los em prática. Quanto à orientação ao mercado, seria a forma de levar esses conceitos teóricos para a realidade. Segundo os autores KOHLI e JAWORSKI (1990), uma orientação para o mercado pressupõe um ou mais departamentos envolvidos em atividade voltada ao desenvolvimento de uma compreensão das necessidades atuais e futuras dos clientes e dos fatores que as afetam, o compartilhamento dessa compreensão por todos os departamentos e vários deles se engajando em atividades planejadas para satisfazer as necessidades de clientes. Seria uma organização cujas ações são consistentes com o conceito de marketing. Em outras palavras, as atividades do marketing não devem ficar restritas ao próprio departamento, mas compartilhadas por todos os atores de uma determinada organização.

Quando se pensa no contexto universitário, torna-se muito fácil perceber essa questão: o marketing é praticado fundamentalmente pelos professores e seus alunos. A interação maior em todo esse processo ocorre mesmo dentro das salas de aulas, no contato alunos-docentes. É aí que a comunicação ganha sua maior força. A competência do professor em conduzir seus alunos fará toda a diferença. O interesse do aluno por determinada aula, ou melhor, por 
determinado docente, proporciona-lhe a tão desejada satisfação (COLOMBO, 2005), objetivo fundamental das atividades do marketing .

O aluno, por sua vez, é o maior agente do marketing de uma IES e corrobora para a consolidação de um conceito bastante difundido no meio empresarial: um cliente satisfeito leva a sua satisfação a apenas algumas pessoas, às vezes nem mesmo o faz; por outro lado, um cliente aborrecido com uma empresa irá divulgar a sua insatisfação para, ao menos, dez pessoas. "Criar apóstolos e eliminar terroristas deve ser uma meta fundamental para todo fornecedor de serviço” (JONES; SASSER apud LOVELOCK E WRIGHT, 2001: 114).

Um dos pontos importantes a ser considerado na escolha de uma estratégia de marketing é a necessidade de conhecimento da concorrência, seus pontos fortes e também suas fragilidades. A análise da concorrência por uma empresa leva a um aprofundamento do conhecimento de si mesma. Saber quem são seus concorrentes, e até que ponto eles podem fazer frente à empresa, é uma das ferramentas básicas do marketing.

No que se refere às IES privadas, conhecer os seus concorrentes, vislumbrando até que ponto eles podem atingi-las na captação e manutenção do corpo discente é básico para a sua sobrevivência. Muitas vezes, é desse conhecimento que vão se definir as estratégias de marketing mais apropriadas para determinado tempo e local.

Vale ressaltar que as IES públicas também devam ser consideradas nesta análise da concorrência, uma vez que, nos últimos anos, o governo tem aberto novas Universidades, assim como tem aumentado a oferta de vagas nas Universidades Federais. Se essa política for mantida ao longo do tempo, consequentemente, as IES particulares terão menos alunos potenciais.

Da mesma forma, a IES precisa conhecer o perfil de seu público-alvo, principalmente no que se refere ao nível socioeconômico, localização geográfica, expectativas em relação à IES e a um determinado curso. Fato ainda raro no setor, alguns gestores não sabem dizer nem mesmo com precisão quantos alunos possuem, quem dirá conhecê-los mais profundamente? Segundo KALZBECK (2003), a partir da definição e do conhecimento de seu público-alvo que para ele seria o aluno que, além de efetivar matrícula, consegue permanecer na IES por todo o curso, formando-se e às vezes até concluindo lá mesmo a pós-graduação - seria possível executar um planejamento de marketing mais preciso e com um custo menor, pois

Rev. GUAL., Florianópolis, v.4, n. 2, p.167-181, mai/ago. 2011 
não seria necessária uma campanha tão ampla, mas mais focada e provavelmente com melhores resultados.

\section{COMPOSTO DE MARKETING}

O composto, ou Marketing Mix é o conjunto de instrumentos de marketing que a empresa utiliza para atingir seus objetivos de marketing no mercado-alvo. "[...] um composto de marketing é a combinação de ferramentas estratégicas usadas para criar valor para os clientes e alcançar os objetivos da organização.” (CHURCHILL \& PETER, 2000).

O Composto de Marketing pode ser resumido como: produtos ou serviços, preços, distribuição e promoção. Tem como função gerar mais valor aos consumidores e vantagem competitiva em relação aos concorrentes, o que pode ser conseguido através de uma maior capacidade de satisfazer suas necessidades e desejos.

A figura abaixo ilustra como seria o composto de marketing de uma IES. Genericamente seus "produtos ou serviços" seriam os cursos e serviços educacionais; seu "preço", seria o valor cobrado pelas mensalidades; a distribuição, sua localização; e a "promoção" seriam os canais de comunicação interna e externa utilizada. Todas essas ferramentas seriam utilizadas tendo como foco atingir seu público-alvo: o aluno.

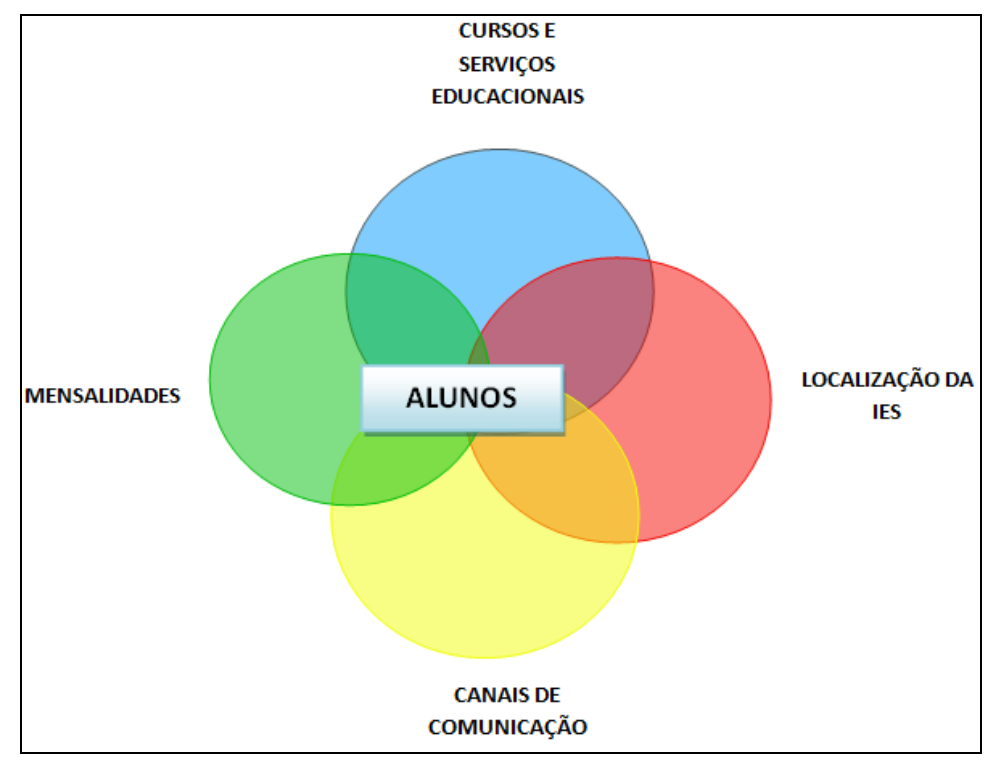

Figura 1 - Composto de Marketing em IES

Fonte: Representação figurativa proposta pelas autoras. 


\section{ESTRATÉGIAS DE MARKETING APLICADAS A INSTITUIÇÕES DE EDUCAÇÃO SUPERIOR PRIVADAS}

\subsection{Produto}

A partir do aprofundamento do contato com seu público-alvo, as IES tomam contato com suas necessidades e expectativas, o que possibilitaria definir melhor seus produtos e serviços, ou seja, quais novos cursos seriam bem sucedidos, assim como quais as mudanças necessárias nos cursos em andamento para alcançar seus objetivos. Essa análise deve incluir uma visão constante e crítica sobre a realidade socioeconômica e política, assim como se desenvolver através do contato com as empresas, para se tomar conhecimento de que tipos de competências estão sendo procuradas em seus funcionários. O conhecimento dos alunos do ensino médio também traz importante retorno sobre a expectativa do futuro público-alvo. Fazer uma oferta de cursos sintonizada com as necessidades desse público, com certeza, é uma excelente opção.

Outro aspecto refere-se ao por que da escolha de uma IES e não de outra. As análises dos fatores que pesam nessa escolha normalmente referem-se a valores das mensalidades, perfil de cursos oferecidos, horários, localização geográfica, missão e imagem institucional. Para se chegar a esses dados, que vão traçar o perfil dos alunos e, consequentemente da IES, a pesquisa de marketing torna-se muito útil e necessária.

Outro fator que pesa muito na escolha de uma IES é opinião do grupo social do candidato; na verdade a rede social a que pertence o candidato é que lhe trará o respaldo para sua escolha. Logo, a imagem institucional e a credibilidade da instituição pesarão muito nessa escolha.

O trabalho dos departamentos de Marketing das IES tem tido como principal preocupação, a captação de novos alunos. Para isso, o foco de seu trabalho está no número de candidatos inscritos nos processos seletivos e principalmente no número de novas matrículas efetivadas. Porém, com o aumento da concorrência, as IES precisam começar a preocupar-se também, como qualquer outro setor que enfrente aumento da concorrência, com a retenção de seus alunos. O gasto com a captação de novos clientes é imensamente maior que o custo da retenção de seus alunos.

Segundo KOTLER (2000: 49), com a evolução do marketing deve-se considerar o valor do cliente ao longo do tempo, deixando de realizar um lucro sobre cada venda para realizar lucros por meio da gestão do valor do cliente ao longo do tempo. Assim, a questão da fidelidade a um produto ou a uma determinada empresa - incluam-se aí as IES - irá garantir a obtenção de lucro ao longo do tempo.

Rev. GUAL., Florianópolis, v.4, n. 2, p.167-181, mai/ago. 2011 
Ainda de acordo com Kotler (2000), o marketing está constantemente sendo redefinido e incorporando novas responsabilidades. O que era considerado anteriormente apenas "a arte de vender produtos", agora passa a ser a ciência de conquistar clientes, mantê-los e aprofundar o relacionamento com eles, aumentando com isso a lucratividade das empresas.

Com a crescente demanda pela educação continuada, ou seja, com a nova visão da educação de que os estudos não terminariam na conclusão do curso de graduação, mas sim que as pessoas precisam se atualizar permanentemente, sempre aprimorando e aprofundando os seus conhecimentos, surge uma interessante possibilidade para a IES: manter o aluno por um período maior assim como trazer de volta os seus egressos.

\subsection{Preços}

Na literatura de marketing, preço é a quantidade de dinheiro cobrada por um produto e/ou serviço. A estratégia de preço deve estar vinculada à estratégia geral da empresa, isto é, seu posicionamento no mercado. O marketing pode colaborar com as empresas na determinação de qual seria o preço ótimo para um determinado produto, dado seu posicionamento no mercado. Para se determinar o preço de um produto ou serviço devem-se determinar as variáveis: custo, concorrentes e mercado. Para isso, sem sombra de dúvidas, é preciso levar em conta a dinâmica do mercado. A escolha do público-alvo e do segmento, em Marketing, é o que se denomina posicionamento.

Devido ao fato de os serviços serem uma promessa, um vir-a-ser, mais difícil ainda é a fixação de seu preço. É preciso levar em conta, também, que o consumidor exigirá sempre uma qualidade mínima, por mais baixo que seja o preço do serviço, para que considere que houve a prestação de serviço. Na verdade, o usuário paga por sua expectativa em relação a um serviço. Nesse sentido, preços de produtos são mais facilmente comparáveis que preços de serviços.

Nas IES o estabelecimento do valor das mensalidades é algo bastante difícil, pois atrelada ao valor estipulado, entra a questão da imagem da instituição perante seu público. As mensalidades pesam bastante na escolha de uma IES, mas um valor muito baixo pode gerar desconfiança ou mesmo descrédito sobre o serviço que será prestado. Há um componente subjetivo muito forte envolvido na relação valor da mensalidade e expectativa do beneficio do resultado de um curso. 
Como a estratégia de preço está intimamente vinculada ao posicionamento de uma empresa no mercado, assim também as IES, ao determinarem os valores de suas mensalidades, devem estar bem conscientes de seu público-alvo e do seu posicionamento no mercado. A posterior alteração de valores é bastante difícil e chega a ser até regulada pela legislação vigente.

Uma estratégia bastante utilizada pelo ensino superior privado é a utilização de uma política de preços variáveis de mensalidades com a adoção de uma escala de descontos ou bolsas de estudos parciais, ou seja, determina-se um valor ideal para cada curso, mas o mesmo é customizado de acordo com a situação financeira do aluno e de seu rendimento acadêmico. Muitas vezes também são ofertados descontos nos turnos menos concorridos. Essas medidas fazem com que se aumente o número de matrículas. Como diz Kalzbeck (2003: 42): “Ao invés de ensinar em uma sala de aula com a metade das carteiras desocupadas, as faculdades e as universidades estão oferecendo desconto nas mensalidades para melhor utilizar a capacidade ociosa. É melhor lucrar com $75 \%$ do valor da mensalidade de um aluno do que ter uma cadeira desocupada".

Como a política de preços no segmento educacional determina boa parte das escolhas por uma IES, principalmente com base no fato de que, ao optarem por uma IES privada, com determinado valor de mensalidade, os estudantes sabem que terão de arcar com esses valores por um período de tempo relativamente longo, no mínimo entre 24 e 30 meses; além do que eles têm também a noção de que somente alcançarão o benefício se conseguirem atravessar com êxito todo esse percurso. Assim, as IES devem monitorar com especial atenção esse item.

Outra importante questão é que a adoção de uma estratégia baseada apenas na questão dos valores, do ponto de vista das teorias de marketing, seria considerada muito frágil, vulnerável, devendo ser parte de um plano maior de estratégias.

\subsection{Praça}

A praça é outro importante ponto de uma estratégia de marketing, pois indica a maneira como ocorrerá distribuição de seus produtos e serviços. Refere-se à maneira pela qual a empresa vai tornar seus produtos e serviços disponíveis para uso ou consumo. A distribuição, na maior parte das vezes, é um fator estratégico para as empresas. 
No contexto educacional, a localização de uma IES pode ser considerada um facilitador aos alunos. Mas com o advento dos cursos superiores oferecidos à distância (EAD) e as facilidades de deslocamento que passaram a existir mesmo nas grandes cidades, não pode ser considerado um fator tão importante, apenas deve ser considerado junto aos demais itens que compõe o Marketing mix.

\subsection{Promoção}

A promoção é outro ponto de fundamental importância para o marketing. Para que se estabeleça uma boa comunicação é imprescindível um bom conhecimento do público-alvo. A escolha dos canais de comunicação deve estar relacionada com as características desse público. A questão do posicionamento também deve ser levada em conta na escolha desses canais.

Eis um ponto absolutamente importante nas IES: a comunicação, interna e externa, não somente com o possível aluno, com o aluno e com o egresso, mas sim com toda a comunidade. É através da comunicação que a instituição conseguirá passar a sua imagem, sua missão, seus objetivos. Hoje, muito mais facilmente com a ajuda da internet. O site pode ser um grande aliado nesse trabalho; através dele as IES podem, a um custo muito acessível, resolver boa parte de sua comunicação. O site deve ser útil não apenas na captação de novos alunos, mas durante todo o tempo do curso e mesmo depois da formatura. Deve conter informações relevantes para todos os seus públicos, conforme demonstrado na ilustração a seguir.

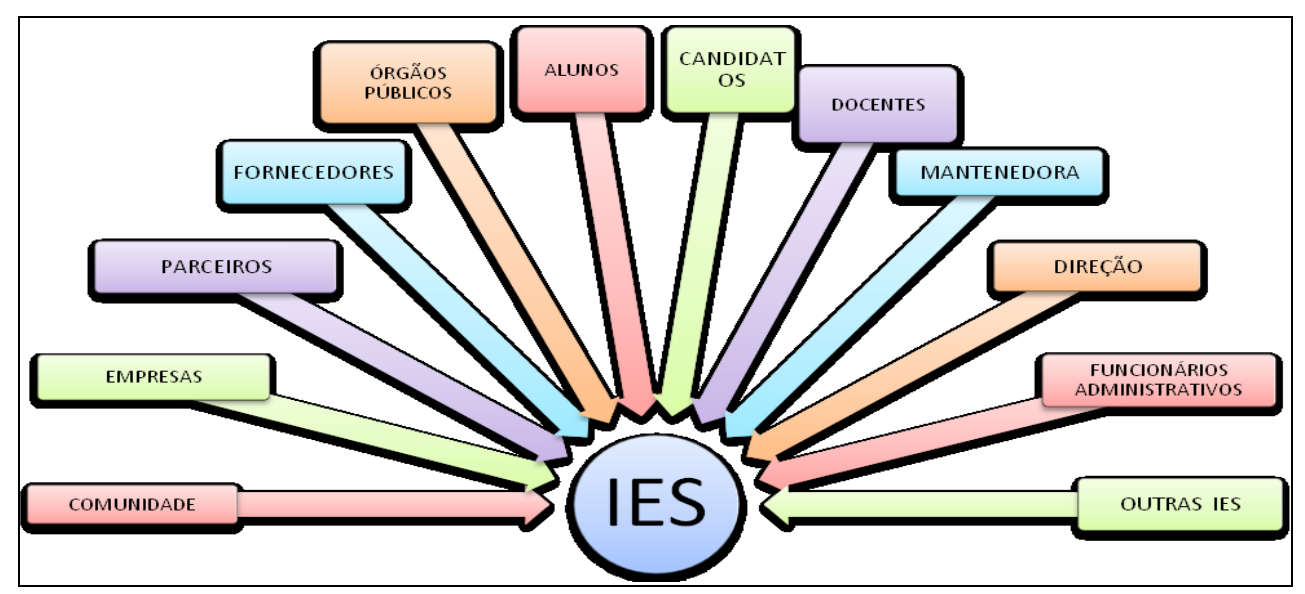

Figura 2 - Públicos de uma IES

Fonte: Representação figurativa proposta pelas autoras, com base em Kotler. 
Os profissionais de marketing devem elaborar estratégias que se adaptem à posição e aos recursos da empresa face aos seus concorrentes e, depois, gerenciar e adaptar de maneira eficaz essas estratégias para atenderem às alterações do ambiente. Um bom composto de marketing pode ser um diferencial para uma empresa.

\section{CONSIDERAÇÕES FINAIS}

Após a análise dos problemas que envolvem, nos dias de hoje, a questão a oferta do ensino superior pelas IES particulares, levantou-se a possibilidade de solução para os mesmos, através da adoção de uma política voltada para estruturas de marketing apropriadas e eficientes na captação e manutenção de alunos numa instituição de ensino. Com esse recurso, entre outros, as particulares não apenas podem concorrer com as públicas na captação de alunos, mas oferecer condições de educação continuada a uma ampla parcela da comunidade, que busca no ensino superior, além da formação ou especialização profissional, a realização pessoal.

Logicamente, não são todas as IES que vão expandir suas atividades através da abertura de capital para o mercado, mas, a grande maioria busca a realização da sua missão, em grande parte voltada para o ensino, a educação e a cultura neste país.

Observou-se, no correr deste texto, que o marketing, no contexto universitário, é praticado fundamentalmente pela boa relação entre alunos e docentes, principalmente em sala de aula. E que, nessa relação, o papel do aluno como agente de marketing é decisivo para a divulgação da IES, levando para a comunidade tanto os seus aspectos positivos, quanto negativos.

Tomando essas considerações como base, pode-se chegar à conclusão de que os maiores investimentos a serem feitos por uma IES, do ponto de vista do marketing educacional, está tanto na oferta de uma educação de boa qualidade, através da contratação de bons professores e demais prestadores de serviço, quanto em melhorias contínuas na infraestrutura, de modo a contemplar as expectativas do alunado, que na IES escolhida deposita toda a sua confiança e credibilidade. É preciso manter em alta a credibilidade dos serviços oferecidos pela instituição, para que o aluno, uma vez se matriculando, nela permaneça e, após o término do curso, seja um agente positivo na divulgação da IES para a 
sociedade. Tudo isso se consegue a partir do uso bom e adequado de estratégias de marketing bem constituídas.

\section{REFERÊNCIAS:}

AMERICAN Marketing Association. AMA. Definition of marketing. Disponível em http://www.marketingpower.com/Community/ARC/Pages/Additional/Definition/default.aspx Acessado em 28 jul. 2011.

CHURCHILL JR, Gilbert A., PETER, J. P. Marketing: criando valor para os clientes. 2. ed. São Paulo: Saraiva, 2000.

COLOMBO, Sonia Simões. (org). Marketing educacional em ação: estratégias e ferramentas. Porto Alegre: Artemed/Bookman, 2005.

COLOMBO, Sonia Simões (org). Desafios da Gestão Universitária Contemporânea. Porto Alegre: Artmed, 2011.

COLOMBO, Sonia Simões \& CARDIM, Paulo A. Gomes (org.). Nos Bastidores da Educação Brasileira - A Gestão vista por dentro. Porto Alegre: Artmed Editora, 2010.

INEP - INSTITUTO NACIONAL DE ESTUDOS E PESQUISAS ANÍSIO TEIXEIRA disponível em: http://www.inep.gov.br/download/censo/2008/resumo_tecnico_2008_15_12_09.pdf Acesso em: 28.07.2011

KALSBEK, David H. Marketing e gerenciamento de matrículas na educação superior. In: MEYER, Victor Jr, Dinossauros, Gazelas \& Tigres - Novas Abordagens da Administração universitária. Um diálogo Brasil e EUA. Florianópolis: Insular, 2003, p.123-150.

KOHLI, A. K. e JAWORSKI, B.. Market orientation: the construct, research propositions and managerial aplications. In: The Journal of Marketing. vol. 54, p. 1-18, April 1990.

KOTLER, Philip. Marketing para o século XXI: como criar, conquistar e dominar mercados. São Paulo: Futura, 2000.

KOTLER, Philip \& LEVY, Sidney J. Broadening the Concept of Marketing. The Journal of Marketing. American Marketing Association, Vol. 33, No. 1 (Jan., 1969), pp. 10-15.

Disponível:

http://www.marketingpower.com/ResourceLibrary/JournalofMarketing/Pages/1969/33/1/5001 255.aspx . Acessado em 10/05/2011, 08:41. 
KOTLER, Philip. Valor com valor se paga. HSM Management. v.5,nº 19, p.6-16, março, 2000.

KOTLER, P. Armstrong.G. Princípios de Marketing. 7.ed.Rio de Janeiro: Prentice Hall do Brasil, 1998.

LIMA, M.C. Globalização ou internacionalização do ensino superior? In: Revista de ESPM, Vol. 13, Ano 12, Ed. 4, Julho/Agosto, pp. 80-90, 2006.

LOVELOCK, C.; WRIGHT, L. Principles of service marketing and management. New Jersey: Prentice-Hall, 1999.

MINISTÉRIO DA EDUCAÇÃO. Lei no 9.394/96, de Diretrizes e Bases da Educação Nacional.

MUND, A.L.; DURIEUX, F.; TONTINI, G. A influência do marketing na opção do aluno pela Universidade Regional de Blumenau. In: CONGRESSO BRASILEIRO DE CIÊNCIAS DA COMPUTAÇÃO, 24, 2001, Campo Grande. Anais... Campo Grande, XXIV Congresso Brasileiro de Ciências da Computação, 2001.

WALTER, S.A.; TONTINI, G.; DOMINGUES, M.J.C.S. Identificando oportunidades de melhoria em um curso superior através da análise da satisfação dos alunos. In: ENCONTRO NACIONAL DOS PROGRAMAS DE PÓS-GRADUAÇÃO EM ADMINISTRAÇÃO, 29, 2005. Anais. Brasília. XXIX ENANPAD, 2005 


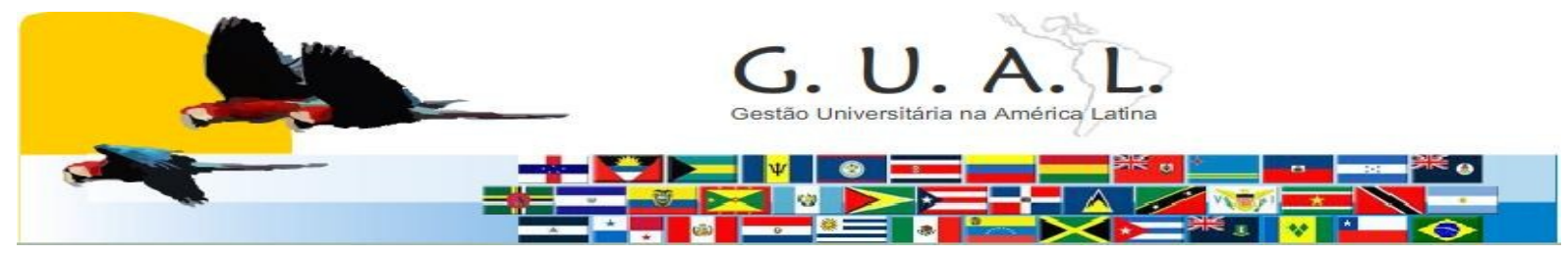

ISSN 1983-4535

\title{
MARKETING STRATEGIES APPLIED TO PRIVATE UNIVERSITIES
}

\author{
Vera Lucia Telles Scaglione, Bacharel \\ Faculdade Paulista de Artes - FPA \\ vera.fpa@terra.com.br \\ Vera Toledo Piza, Doutora \\ Faculdade Paulista de Artes - FPA \\ vtpiza@uol.com.br
}

\begin{abstract}
From the beginning of the $21^{\text {st }}$ century, many changes have occurred in the Brazilian cultural scene, especially with regard to the quest for higher education. This is due to increase in the purchasing power of social classes, who seek in higher education both professional growth and personal fulfillment. This phenomenon has generated a growing number of universities in all areas in the country, both public and private. This text provide an analysis of this reality based on literature developed by authors of marketing area, concluding that the private educational institutions need the support of education marketing, that will suggest appropriate strategies to facilitate the capture and maintenance of students in the universities. The students, satisfied with the quality of education offered to them, will act as marketing agents, communicating to the society the qualities of services that were provided by the university.
\end{abstract}

Keywords: Competitiveness; Performance; Higher Education; Marketing Strategies. 